\title{
High anti-Ascaris seroprevalence in fattening pigs in Sichuan, China, calls for improved management strategies
}

\author{
Youle Zheng ${ }^{1 \dagger}$, Yue Xie ${ }^{1 \dagger}$, Peter Geldhof ${ }^{2^{*}}$, Johnny Vlaminck ${ }^{2}$, Guangxu Ma ${ }^{3}$, Robin B. Gasser ${ }^{3}$ and Tao Wang ${ }^{33^{*}}$ (D)
}

\begin{abstract}
Background: Ascariasis, caused by Ascaris suum, is an important soil-transmitted parasitic disease of pigs worldwide. It leads to significant economic losses in the pork industry, as a consequence of low feed conversion efficiency in pigs and liver condemnation at slaughter. Despite ascariasis still being widespread on pig farms in many developing and the industrialised countries, there are surprisingly limited data on porcine ascariasis in China, where nearly half of the world's total pork is produced.

Methods: In the present study, using the recently developed A. suum-haemoglobin (As-Hb) antigen-based serological test, we screened 512 individual serum samples from fattening pigs from 13 farms across seven distinct locations of Sichuan Province in China for anti-Ascaris antibody.

Results: The prevalence of anti-Ascaris antibody ranged from $0 \%$ to $100 \%$ on the distinct farms, with the mean (overall) seroprevalence being $>60 \%$. There was no significant difference in seroprevalence between the intensive and extensive farms.

Conclusions: To our knowledge, this is the first study to measure anti-Ascaris seroprevalence in China. The results of this 'snapshot' investigation indicate that Ascaris infection in commercial pig farms in Sichuan Province is seriously underestimated, encouraging future, large-scale serological studies to assess the distribution and extent of Ascaris exposure and infection in various regions of China and the world.
\end{abstract}

Keywords: Pig, Ascaris suum, Seroprevalence, Serodiagnosis, As-Hb-based ELISA

\section{Background}

Ascariasis, caused by Ascaris suum, is one of the most important and commonest soil-transmitted parasitic diseases of pigs worldwide. This disease leads to major economic losses to the pork industry as a consequence of

\footnotetext{
*Correspondence: Peter.Geldhof@UGent.be; tao.wang1@unimelb.edu.au

${ }^{\dagger}$ Youle Zheng and Yue Xie contributed equally to this work

${ }^{2}$ Laboratory of Parasitology, Department of Virology, Parasitology and Immunology, Faculty of Veterinary Medicine, Ghent University, 9820 Merelbeke, Belgium

${ }^{3}$ Department of Veterinary Biosciences, Melbourne Veterinary

School, Faculty of Veterinary and Agricultural Sciences, The University of Melbourne, Parkville, VIC 3010, Australia

Full list of author information is available at the end of the article
}

reduced weight gain and low feed conversion efficiency in pigs [1] and liver condemnation at slaughter [2]. Currently, losses due to ascariasis have been estimated as at $\geq € 4.61$ per finisher pig per year [3]. In the field, A. suum is often undiagnosed and neglected due to the subclinical nature of infection [4]. Estimates of prevalence and intensity of Ascaris infection or exposure on commercial pig farms, achieved using diagnostic tools, support treatment and control programs, and importantly, guide farm management and hygiene practices [5].

A number of diagnostic techniques are available for the detection or assessment of Ascaris infection in pigs. They include the qualitative and quantitative flotation of eggs of this nematode from faecal samples; post-mortem



(c) The Author(s) 2020. This article is licensed under a Creative Commons Attribution 4.0 International License, which permits use, sharing, adaptation, distribution and reproduction in any medium or format, as long as you give appropriate credit to the original author(s) and the source, provide a link to the Creative Commons licence, and indicate if changes were made. The images or other third party material in this article are included in the article's Creative Commons licence, unless indicated otherwise in a credit line to the material. If material is not included in the article's Creative Commons licence and your intended use is not permitted by statutory regulation or exceeds the permitted use, you will need to obtain permission directly from the copyright holder. To view a copy of this licence, visit http://creativecommons.org/licenses/by/4.0/. The Creative Commons Public Domain Dedication waiver (http://creativecommons.org/publicdomain/zero/1.0/) applies to the data made available in this article, unless otherwise stated in a credit line to the data. 
examination for adult worms or liver lesions; and antibody-based serological tests [6]. Of these diagnostic methods, the recently developed A. suum haemoglobin $(A s-\mathrm{Hb})$ antigen-based enzyme-linked immunosorbent assay (ELISA) test was shown to achieve a higher sensitivity than conventional (qualitative) faecal flotation [7]. Specifically, in well-controlled experimental infection studies, this serodiagnostic tool achieved $99-100 \%$ specificity and $90-99.5 \%$ sensitivity for detecting the exposure to A. suum in fattening pigs [7]. In addition, this serological tool appeared to be able to estimate infection intensity, pig health and farm productivity [8], indicating that it can be used to guide farm management practices and worm control programs.

China provides nearly $50 \%$ of the world's total pork production each year [9]. Although the pork industry contributes substantially to the fast-growing agricultural economy in China, surprisingly limited attention has been paid to infectious diseases including ascariasis. To date, only a small number of coprological surveys of pigs for A. suum infection have been conducted on pig farms in the provinces of Hunan (prevalence: 37\%; [10]), Chongqing (12\%; [11]) and Guangdong (5\%; [12]). In the present study, using $A s-\mathrm{Hb}$ antigen-based ELISA, we conducted the first seroprevalence survey to evaluate $A$. suum exposure in fattening pigs of 13 pig farms from seven locations in Sichuan Province, which alone produce $10 \%$ of the total amount of pork (per annum) in China [13].

\section{Methods}

\section{Study population and sample collection}

From 2015 to 2017, a total of 512 fattening pigs (>90 kg, 7 months of age) from 11 intensive pig farms and two extensive farms were sampled in Sichuan Province (Fig. 1). In most intensive farms, pigs were kept on fully- or semi-slatted concrete floors, with anthelmintic treatment (e.g. fenbendazole or ivermectin) every three months and high-pressure cleaning of pens after each fattening cycle. On extensive farms, pigs were kept outside without protection from the elements, where they were closely associated with human residences and often fed on household food-waste, with only one anthelmintic treatment (e.g. fenbendazole or ivermectin) during each fattening cycle. Sera were prepared from blood samples following an established protocol [8]. Briefly, blood samples were incubated at $37{ }^{\circ} \mathrm{C}$ for $1 \mathrm{~h}$ and then refrigerated $\left(4{ }^{\circ} \mathrm{C}\right)$ for $1 \mathrm{~h}$. The sera were then removed from the clot, and centrifugated at $4000 \times g$ for $10 \mathrm{~min}$ at $4{ }^{\circ} \mathrm{C}$. The supernatants were collected and stored at $-20{ }^{\circ} \mathrm{C}$ until testing.

\section{ELISA testing of serum samples}

Serum samples were tested as described previously [7]. Briefly, ELISA plates were coated with $A s-\mathrm{Hb}(1 \mu \mathrm{g} / \mathrm{ml})$ in carbonate buffer $(\mathrm{pH} 9.6)$ at $4{ }^{\circ} \mathrm{C}$ for $18 \mathrm{~h}$, washed three times with phosphate-buffered saline (PBS) plus $0.5 \%(\mathrm{v} / \mathrm{v} /)$ Tween 20 (Sigma-Aldrich, St. Louis, USA) $(\mathrm{PBST})$ and then blocked with $5 \%(\mathrm{w} / \mathrm{v})$ milk powder in




PBS (PBSM) at $4{ }^{\circ} \mathrm{C}$ for $2 \mathrm{~h}$. The primary antibody was then added at a dilution of $1 / 250$ in PBST and incubated at $4{ }^{\circ} \mathrm{C}$ for $2 \mathrm{~h}$. The plates were washed three times, conjugate (horseradish peroxidase conjugated goat anti-pig IgG, 1/10,000) (Sigma-Aldrich) added and incubated with PBSM at $37^{\circ} \mathrm{C}$ for $1 \mathrm{~h}$. Following three final washes with PBST, the substrate o-phenylenediamine $0.1 \%$ in citrate buffer ( $\mathrm{pH}$ 5.0) was added and the optical density (OD) measured at $492 \mathrm{~nm}$. Positive and negative sera were included on each plate. ELISA results were reported as the average optical density ratio (ODR) per farm: OD sample $=\left(\mathrm{OD}_{\text {Sample }}-\mathrm{OD}_{\text {Negative }}\right.$ Control $) /\left(\mathrm{OD}_{\text {Positive }}\right.$ Control $\left.-\mathrm{OD}_{\text {Negative Control }}\right)$ and percentage of test-positive animals. The ELISA threshold (between positive and negative) was set at 0.50 .

\section{Statistical analysis}

To assess differences in seroprevalence in pigs among different locations and farms, the Chi-square test, one-way analysis of variance (ANOVA) and independent $\mathrm{t}$-test were performed. Probability $(P)$ values $<0.05$ were considered as statistically significant, and the $95 \%$ confidence interval (CI) was used. All analyses were performed using the SPSS Statistics 24 software package (IBM, New York, USA).

\section{Results and discussion}

Using the As-Hb-based ELISA, 512 individual serum samples of fattening pigs from 13 farms from seven distinct locations of Sichuan Province (Fig. 1) were screened for specific anti-Ascaris antibody. In total, $60.7 \%(n=311)$ of the serum samples were test-positive $(\mathrm{OD}>0.5)$ for anti-Ascaris antibodies, with seroprevalence ranging from $14.3 \%$ to $100 \%$ on 12 fattening farms (Fig. 2; Table 1). Seropositive samples were detected in all locations studied in Sichuan Province. Farm A from Chengdu was the only farm on which no test-positive sera were

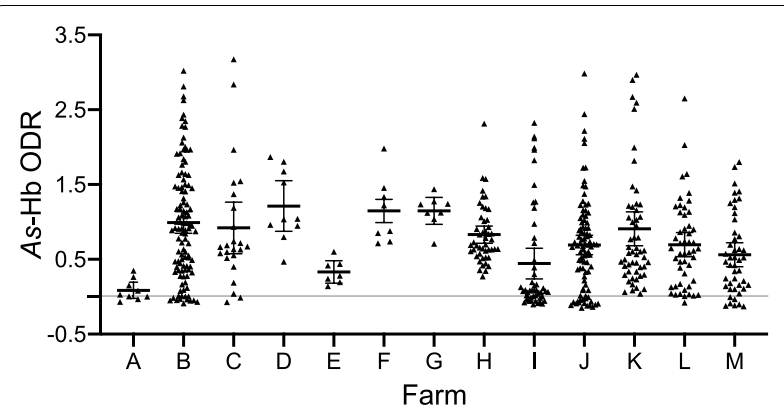

Fig. 2 Dot plots displaying optical density ratio (ODR) levels (mean \pm standard error, SE) for anti-Ascaris antibodies. ODR levels were measured by ELISA in 512 individual serum samples from 13 pig farms (farms A-M; Table 1) in Sichuan Province, China. The horizontal line indicates the cut-off value of ODR $=0.50$ detected, which is likely due to the relatively small sample size $(n=9)$ tested. Of the eight farms with relatively large sample sizes $(n>20)$, Farm $C$ from the same location as Farm A (i.e. Chengdu) showed the highest seroprevalence (79.2\%; 19/24; average ODR of 0.92$)$, whereas Farm I from Mianyang had the lowest prevalence $(26.0 \%$; 13/50; average ODR of 0.44). A comparison with findings from previous reports in China showed that the overall Ascaris exposure rate in fattening pigs in Sichuan Province (i.e. 60.7\%; 311/512; average ODR of 0.78) was markedly higher than that of any other reported regions, such as the provinces Hunan $(26.1 \% ; d f=1 ; P<0.001 ;[10])$, Chongqing $(12.2 \% ; d f=1 ; P<0.001 ;[11])$ and Guangdong (5.2\%; $d f=1 ; P<0.001 ;[12])$. Notably, all previous investigations were based on the examination of faecal samples for Ascaris eggs, which might have easily underestimated levels of exposure, especially linked to infections with larvae $[6,14]$. Although results obtained using the present antigen-based ELISA test indicated a high exposure to $A$. suum on the pig farms studied in Sichuan Province and might be representative, it is possible that the limited number of farms studied and the percentages of animals tested per farm (ranging from $0.23 \%$ to $36 \%$; Table 1) might have led to a bias in seroprevalence recorded on these farms. Thus, in the future, large-scale studies should be conducted to establish, compare and contrast anti-A. suum seroprevalences in fattening pigs within and among other provinces.

It is generally believed that a better housing system and more regular anthelmintic treatment in modern intensive farms will likely reduce the levels of Ascaris infection [15]. This is supported by the previous coprologicalbased studies in other areas of China as well as in other countries $[12,16]$, where $A$. suum burden in intensive pig facilities was found to be lower than that on extensive farms. Interestingly, the present study indicates that major A. suum exposure can occur in both intensive $(62.6 \%, 258 / 412)$ and extensive $(53.0 \%, 53 / 100)$ farms in Sichuan Province, with no significant difference between them $\left(x^{2}=3.124, d f=1, P=0.077\right)$. Although this finding is challenging to explain, it might relate to the management practices used on the farms studied. For most farms, pigs were imported from local piglet producers, where the management and hygiene conditions were different. In addition, the all-in/all-out production system was not strictly followed in the fattening round on the intensive farms studied (TW, unpublished information). Following initial Ascaris egg-contamination, the high stocking density in intensive farms likely led to increased transmission of A. suum. It is also worth noting that anthelmintic treatment of pigs on these farms was performed every three months on a regular basis. Given the prepatent period of the life-cycle of Ascaris ( 42 days; 
Table 1 Summary of anti-Ascaris serum antibody prevalence in pigs from thirteen farms in Sichuan, China (cf. Fig. 1)

\begin{tabular}{lllllll}
\hline Location & Farm & $\begin{array}{l}\text { No. of } \\
\text { samples } \\
\text { tested }\end{array}$ & $\begin{array}{l}\text { No. of samples test-positive for } \\
\text { anti-Ascaris antibody (\%) }\end{array}$ & Average ODR \pm SD & 95\% Cl & Total no. of pigs per farm \\
\hline Chengdu & Farm A (intensive) & 9 & $0(0.0)$ & $0.09 \pm 0.14$ & $-0.02-0.2$ & $1600-2000$ \\
& Farm B (intensive) & 108 & $73(67.6)$ & $0.99 \pm 0.76$ & $0.85-1.13$ & $5000-6000$ \\
& Farm C (intensive) & 24 & $19(79.2)$ & $0.92 \pm 0.81$ & $0.58-1.26$ & $3500-3800$ \\
Dazhou & Farm D (intensive) & 10 & $9(90.0)$ & $1.21 \pm 0.47$ & $0.87-1.55$ & $800-1200$ \\
& Farm E (intensive) & 7 & $1(14.3)$ & $0.33 \pm 0.16$ & $0.18-0.48$ & $1000-2000$ \\
& Farm F (intensive) & 8 & $8(100.0)$ & $1.15 \pm 0.44$ & $0.78-1.52$ & $3500-4700$ \\
Deyang & Farm G (intensive) & 8 & $8(100.0)$ & $1.15 \pm 0.21$ & $0.98-1.33$ & $1100-1200$ \\
Mianyang & Farm H (intensive) & 47 & $40(85.1)$ & $0.83 \pm 0.39$ & $0.72-0.94$ & $10,000-11,000$ \\
& Farm I (intensive) & 50 & $13(26.0)$ & $0.44 \pm 0.72$ & $0.24-0.64$ & $11,000-13,000$ \\
Ya'an & Farm K (extensive) & 54 & $56(61.5)$ & $0.69 \pm 0.63$ & $0.56-0.82$ & $10,000-12,000$ \\
Yibing & Farm L (intensive) & 50 & $31(57.4)$ & $0.91 \pm 0.83$ & $0.69-1.13$ & $120-150$ \\
Suining & Farm M (extensive) & 46 & $22(47.8)$ & $0.70 \pm 0.57$ & $0.54-0.86$ & $5000-7000$ \\
Total & & 512 & $311(60.7)$ & $0.56 \pm 0.54$ & $0.40-0.72$ & $200-300$ \\
\hline
\end{tabular}

a As an all-in/all-out production system was not strictly followed during the fattening cycle on the farms studied here, the approximate range of the total number of pigs on individual farms during fattening cycles is indicated

Abbreviations: ODR, optical density ratio; $\mathrm{SD}$, standard deviation; $\mathrm{Cl}$, confidence interval

[15]), such a deworming program might not be effective at controlling adult worm burdens and reducing egg contamination in the environment, whereas a six-weekly deworming programme has proven to be efficacious for the control the Ascaris infection in intensive piggeries, and was shown also to improve the performance parameters (e.g. feed conversion ratio and average daily growth) in pigs [17]. Preferably, such an efficient deworming program should be introduced on 'pig fattening' farms dealing with the challenges of a high prevalence of Ascaris.

\section{Conclusions}

We employed the $A s-\mathrm{Hb}$ antigen-based ELISA assay to measure the seroprevalence of A. suum infection/exposure on the fattening pig farms in Sichuan Province, China. To our knowledge, this is the first time that a serological screening test has been applied in China. The result of this 'snapshot' investigation indicate that Ascaris infection in commercial pig farms in Sichuan Province is seriously underestimated, encouraging future largescale serological studies in different regions of China for a better understanding of the distribution and extent of Ascaris exposure and infection. Such a focus should contribute to an improved approach to the control of porcine ascariasis both in China and many other countries around the world.

\section{Abbreviations}

As-Hb: A. suum haemoglobin; Cl: confidence interval; ELISA: enzyme-linked immunosorbent assay; OD: optical density; ODR: optical density ratio; PBS: phosphate-buffered saline; PBST: phosphate-buffered saline plus 0.5\% (v/v/) Tween 20; PBSM: PBS with 5\% (w/v) milk powder; SE: standard error.

\section{Acknowledgements}

We thank Drs. Zhiwen Xu and Yiping Wen (College of Veterinary Medicine, Sichuan Agricultural University, China) for providing serum samples. We are grateful to Ms. Nathalie De Wilde and Isabelle Despeghel for their support with serological testing.

\section{Authors' contributions}

TW and PG planned the study. TW, JV and PG undertook the laboratory work. TW analysed the results. TW, YZ and RBG wrote the manuscript with inputs from $Y X, G M, X G$ and $P G$. TW and PG raised the funds for the project. All authors read and approved the final manuscript.

\section{Funding}

This project was supported by the International Cooperation Projects of Sichuan Science and Technology Department of Sichuan Province, China Program 2014HH0047 (TW and PG). The funding body played no role in the design of the study or sample collection, data analysis or interpretation, or in the writing of the manuscript.

\section{Availability of data and materials}

Data supporting the conclusions of this article are included within the article.

\section{Ethics approval and consent to participate}

The ethical approval of sample collection was obtained from the Animal Care and Use Committee of Sichuan Agricultural University (code: SYXK2019-187). All sample collections were conducted following the ARRIVE guidelines (http://www.nc3rs.org.uk/arrive-guidelines).

\section{Consent for publication}

Not applicable.

\section{Competing interests}

The authors declare that they have no competing interests.

\section{Author details}

${ }^{1}$ College of Veterinary Medicine, Sichuan Agricultural University,

Chengdu 611130, Sichuan, People's Republic of China. ${ }^{2}$ Laboratory 
of Parasitology, Department of Virology, Parasitology and Immunology, Faculty of Veterinary Medicine, Ghent University, 9820 Merelbeke, Belgium. ${ }^{3}$ Department of Veterinary Biosciences, Melbourne Veterinary School, Faculty of Veterinary and Agricultural Sciences, The University of Melbourne, Parkville, VIC 3010, Australia.

Received: 18 November 2019 Accepted: 3 February 2020 Published online: 12 February 2020

\section{References}

1. Hale OM, Stewart TB, Marti OG. Influence of an experimental infection of Ascaris suum on performance of pigs. J Anim Sci. 1985;60:220-5.

2. Perez J, Garcia PM, Mozos E, Bautista MJ, Carrasco L. Immunohistochemical characterization of hepatic lesions associated with migrating larvae of Ascaris suum in pigs. J Comp Pathol. 2001;124:200-6.

3. Van Meensel J, Kanora A, Lauwers L, Jourquin J, Goossens L, Van Huylenbroeck $G$. From research to farm: ex ante evaluation of strategic deworming in pig finishing. Vet Med-Czech. 2010;55:483-93.

4. Roepstorff A, Nansen P. Epidemiology and control of helminth infections in pigs under intensive and non-intensive production systems. Vet Parasitol. 1994;54:69-85.

5. Martinez-Perez JM, Vandekerckhove E, Vlaminck J, Geldhof P, MartinezValladares M. Serological detection of Ascaris suum at fattening pig farms is linked with performance and management indices. Vet Parasitol. 2017;248:33-8

6. Vlaminck J, Levecke B, Vercruysse J, Geldhof P. Advances in the diagnosis of Ascaris suum infections in pigs and their possible applications in humans. Parasitology. 2014;141:1904-11.

7. Vlaminck J, Nejsum P, Vangroenweghe F, Thamsborg SM, Vercruysse J, Geldhof P. Evaluation of a serodiagnostic test using Ascaris suum haemoglobin for the detection of roundworm infections in pig populations. Vet Parasitol. 2012;189:267-73.
8. Vlaminck J, Dusseldorf S, Heres L, Geldhof P. Serological examination of fattening pigs reveals associations between Ascaris suum, lung pathogens and technical performance parameters. Vet Parasitol. 2015;210:151-8.

9. Gilbert M, Conchedda G, Van Boeckel TP, Cinardi G, Linard C, Nicolas G et al. Income disparities and the global distribution of intensively farmed chicken and pigs. PLoS One. 2015;10:e0133381.

10. Boes J, Willingham AL 3rd, Fuhui S, Xuguang H, Eriksen L, Nansen P, Stewart TB. Prevalence and distribution of pig helminths in the Dongting Lake Region (Hunan Province) of the People's Republic of China. J Helminthol. 2000;74:45-52.

11. Lai M, Zhou RQ, Huang HC, Hu SJ. Prevalence and risk factors associated with intestinal parasites in pigs in Chongqing, China. Res Vet Sci. 2011:91:e121-4

12. Weng YB, Hu YJ, Li Y, Li BS, Lin RQ, Xie $D H$, et al. Survey of intestinal parasites in pigs from intensive farms in Guangdong Province, People's Republic of China. Vet Parasitol. 2005;127:333-6.

13. Sichuan Provincial Statistical Yearbook 2016. 2016. http://tij.sc.gov.cn/ tjcbw/tjnj/2016/zk/indexeh.htm. Accessed 28 Jan 2020.

14. Thamsborg SM, Nejsum P, Mejer H. Impact of Ascaris suum in Livestock. In: Holland C, editor. Ascaris: the neglected parasite. Amsterdam: Elsevier; 2015. p. 363-81.

15. Crompton DWT. Ascaris and ascariasis. Adv Parasitol. 2001;48:285-375.

16. Kabululu ML, Ngowi HA, Kimera SI, Lekule FP, Kimbi EC, Johansen MV. Risk factors for prevalence of pig parasitoses in Mbeya Region, Tanzania. Vet Parasitol. 2015;212:460-4.

17. Vandekerckhove E, Vlaminck J, Sacristan RDP, Geldhof P. Effect of strategic deworming on Ascaris suum exposure and technical performance parameters in fattening pigs. Vet Parasitol. 2019;268:67-72.

\section{Publisher's Note}

Springer Nature remains neutral with regard to jurisdictional claims in published maps and institutional affiliations.
Ready to submit your research? Choose BMC and benefit from

- fast, convenient online submission

- thorough peer review by experienced researchers in your field

- rapid publication on acceptance

- support for research data, including large and complex data types

- gold Open Access which fosters wider collaboration and increased citations

- maximum visibility for your research: over 100M website views per year

At BMC, research is always in progress.

Learn more biomedcentral.com/submissions 